\title{
SINERGIA
}

REVISTA DO INSTITUTO DE CIÊNCIAS ECONÔMICAS, ADMINISTRATIVAS E CONTÁBEIS (ICEAC)

\section{A DISPOSIÇÃO A PAGAR PELA COMPENSAÇÃO DA EMISSÃO DE CARBONO NO RIO GRANDE DO SUL: UM ESTUDO PARA A INDÚSTRIA COM ALTO POTENCIAL POLUIDOR}

BRUNO SILVEIRA GOULART*

AUGUSTO MUSSI ALVIM"

\section{RESUMO}

O crescimento dos mercados voluntários de carbono, que visam compensar a emissão dos gases de efeito estufa, reflete o aumento da preocupação das empresas com um estilo de produção mais limpa. Através do Método de Valoração Contingente é analisada a disposição a pagar que as maiores empresas do Rio Grande do Sul têm a fim de compensar suas emissões de carbono via aquisição de créditos. Os resultados apontam que a maior parte destas empresas tem interesse em participar do mercado. Entre as variáveis que influenciam a DAP estão o faturamento e a presença de um setor ambiental na empresa. Conclui-se que existe um mercado potencial para a negociação de créditos de carbono no estado, o qual pode ser expandido caso haja uma regulamentação adequada e uma difusão maior de conhecimento.

Palavras-chave: Créditos de carbono. Disposição a pagar. Compensação de emissões.

\section{ABSTRACT}

The increase of voluntary carbon markets to offset the greenhouse gas emission reflects the concern about cleaner production and its benefits reducing the costs and changing the posture of the consumers. Using this method, it is estimated the willingness to pay of the largest firms from RS. Those firms have to offset their carbon footprint through carbon credits acquisition. The results shows that most companies are interested in participate of this market. The main variables that explain the changes in DAP are the revenue and the presence of an environmental sector in these firms. Finally, in the conclusion, there is a potential market for trade carbon credits in RS, which can be expanded if there is a suit regulation and a reasonable diffusion of knowledge.

Key Words: carbon credits; willingness to pay, offsetting emissions.

Recebido em: 05-01-2016 Aceito em: 20-12-2016.

\section{INTRODUÇÃO}

A questão da importância ambiental dentro das empresas vai além da questão social e dos cuidados básicos com o meio ambiente. Cada vez mais, os consumidores têm preferido buscar informações a respeito da procedência e do destino dos produtos que consomem. A redução de custos, o cumprimento de obrigações legais e a prevenção de multas oriundas de crimes ambientais e o marketing positivo perante os clientes e a sociedade tem feito com que, cada vez mais, as empresas se ajustem a um novo estilo corporativo: o de produção mais limpa.

Apesar de ser um assunto ainda pouco difundido no mundo corporativo, compensar as emissões de gases que provocam o efeito estufa através da participação em mercados de negociação de créditos de carbono vem chamando a atenção das empresas pela facilidade na compensação das emissões, possibilidades de retorno financeiro com a valorização dos créditos e, principalmente, com a responsabilidade social e ambiental que tende a refletir diretamente nos negócios.

Os mercados de carbono têm crescido de forma significativa nos últimos anos. Enquanto no ano de 2005 foram negociados 94,35 milhões de toneladas de CO2, no ano de 2010, esse número chegou a 5,3 bilhões de toneladas de CO2 (ICE, 2011). No Brasil, ainda é pequeno o interesse de participação nesse tipo de negócio, mesmo assim o país é o terceiro maior provedor de projetos do Mecanismo de Desenvolvimento Limpo, forma de compensação originado do Protocolo de Quioto (MCT, 2010). Em contrapartida, de forma voluntária, muitas empresas têm mudado sua filosofia de gestão, produzindo de maneira mais limpa e respeitando os recursos ambientais, antes mesmo que uma regulamentação mais

\footnotetext{
"Mestre em Economia do Desenvolvimento pela Pontifícia Universidade Católica do Rio Grande do Sul

Pós-Doutorado pela Universidade de Massey. Atualmente é Professor Titular da Pontifícia Universidade Católica do Rio Grande do Sul
} 
rígida imponha metas de redução, como ocorre em países da União Europeia.

Dado o potencial existente de comercialização de créditos de carbono no Brasil, o estudo sobre o interesse de participação das empresas nesse tipo de mercado é fundamental para se projetar os melhores caminhos e necessidades em termos de regulação e fomento. Dentre as principais questões discutidas nos últimos anos no Brasil, quando se trata das relações entre a economia e o meio ambiente, estão os processos de associar valores econômicos aos bens e serviços ambientais.

Dessa forma, este trabalho tem por objetivo determinar a disposição a pagar pela compensação das emissões de carbono, equivalente a compra de créditos de carbono pelas empresas gaúchas. Para isso, foi realizada uma pesquisa de campo junto às maiores empresas do estado do Rio Grande do Sul, pertencentes ao setor industrial e com alto potencial poluidor, para avaliar o interesse em participar de um mercado de carbono e valorar o preço justo para a compensação das emissões através do Método de Valoração Contingente.

\section{MÉTODOS E RESULTADOS DE ESTUDOS DE VALORAÇÃO AMBIENTAL NO BRASIL}

Uma das principais questões debatidas atualmente quando se trata das relações entre os sistemas econômicos e os sistemas ambientais refere-se ao processo de se agregar valores econômicos aos bens e serviços ambientais. O processo de valorar recursos ambientais contribui para a tomada de decisão dos agentes econômicos e políticos, permitindo identificar os custos e benefícios, econômicos e sociais, individuais e coletivos relativos ao uso do recurso ambiental.

Os valores dos bens e recursos ambientais podem ser estimados, na medida em que se possa descobrir qual a disposição dos indivíduos a pagar pela preservação ou conservação dos recursos e serviços ambientais. De forma geral, o valor econômico dos recursos ambientais pode ser configurado da seguinte maneira: valor econômico do recurso ambiental (VERA) = valor de uso (VU) + valor de opção (VO) + valor de existência (VE) (MOTTA, 1997).

O valor de uso (VU) representa o valor atribuído pelos indivíduos pelo uso, propriamente dito, dos recursos e serviços ambientais, composto pelo valor de uso direto (VUD) e pelo valor de uso indireto (VUI). $\mathrm{O}$ valor de opção (VO) representa aquilo que os indivíduos atribuem no presente para que, no futuro, os serviços prestados possam ser utilizados. Já o valor de existência (VE), caracteriza-se como um valor de não-uso, como a preservação de riquezas naturais mesmo que ela não represente uso atual ou futuro para o indivíduo (PEREIRA JÚNIOR, 2005).

Existem diversos métodos de valoração que objetivam mensurar as distintas parcelas do valor econômico de um recurso ou serviço ambiental, dentro de suas limitações e estimativas. Para a realização da pesquisa, foi aplicado o Método de Valoração Contingente (MVC). Fundamentado na teoria econômica, este método busca, por meio de entrevistas, revelar as preferências dos indivíduos, a partir da estimativa de sua disposição a pagar DAP (ou disposição a aceitar, DAA) por bens ou serviços ambientais.

Através da simulação de um cenário, busca-se captar a DAP dos indivíduos de acordo com as alterações na disponibilidade dos recursos ambientais para interpretar o quanto estariam dispostos a aceitar a compensação para suportar a perda de um bem-estar. Tal cenário deve estar o mais próximo possível das características do mundo real para que o indivíduo revele suas preferências verdadeiras expressas em valores monetários, que reflita, caso existisse, um mercado para o bem ambiental descrito no cenário hipotético.

Entre as vantagens do MVC, este pode ser aplicado em um espectro de bens ambientais mais amplos. A variação no bem-estar dos indivíduos decorrentes de mudanças de um estado 0 para 1 pode ser captada a partir de medidas de bem-estar como o excedente do consumidor marshalliano, a variação compensatória, a variação equivalente, o excedente equivalente e o excedente compensatório (MOTTA, 1997).

Entre as desvantagens de se utilizar o MVC existe a limitação em captar valores ambientais que os indivíduos não entendem ou pelos respondentes terem incentivos a declarar um valor baixo para o recurso visando reduzir a sua própria contribuição. Além disso, alguns vieses como má especificação do cenário e amostra inadequada e agregação incorreta dos benefícios podem levar a discrepâncias entre as preferências reveladas nas pesquisas e as verdadeiras preferências (MITCHELL E CARSON, 1989).

O interesse pelos métodos de valoração ambiental vem crescendo de forma considerável nos últimos anos, com o aperfeiçoamento das pesquisas de opinião e, principalmente, o fato de ser a única técnica com potencial de captar o valor de existência. Martins (2007) utilizou o MVC para analisar se uma parte do Parque dos Manguezais em Recife-PE deve ou não ser utilizada para a construção de uma rodovia. Através da estimação da disposição a pagar média (DAP - média), foi mostrado que a melhor política a ser adotada é a preservação da área do mangue.

Abreu et al (2008) aplicaram o Método do Custo de Viagem buscando estimar o quanto a população da Praia da Avenida em Maceió ( $\mathrm{AL}$ ) estaria disposta a pagar para custear a sua recuperação. A partir do 
levantamento das médias mensais de visitas a essa e outras praias próximas, conjugadas com as estimativas de custos com transporte e dados populacionais, encontraram na aplicação da metodologia um valor econômico mensal de utilidade recreativa superior a $\mathrm{R} \$ 35$ milhões.

O estudo de Souza (2006) teve por objetivo valorar o uso da água do Rio Paraibuna, a fim de estimar a disposição a pagar dos indivíduos através do MVC, quando foram estimadas as funções de demanda e o excedente do consumidor. O Método de Valoração Contingente e a estimação econométrica de um modelo Probit foram realizados para avaliar a disposição a pagar dos usuários da bacia. Os resultados indicaram que a probabilidade média do indivíduo a apresentar disposição a pagar é de $75,39 \%$ e que o valor da disposição a pagar individual pela despoluição e preservação do rio é de 18,07 reais.

Já o estudo de Holmes et al (1998) estimou a disposição a pagar pela proteção de florestas na região costeira da Mata Atlântica no Nordeste brasileiro. Os autores utilizaram um modelo Probit Ordenado para estimar um conjunto de parâmetros e as mudanças destes ao longo do tempo. Como principais resultados, os autores estimaram a disposição a pagar de 9,08 dólares por pessoa para proteger $7.000 \mathrm{~km}^{2}$ no sul da Bahia.

Kim, House e Kim (2016) examinaram a percepção dos consumidores na Coreia do Sul frente à mudança climática e à disposição a pagar pelos produtos produzidos com baixo carbono e identificados a partir da rotulagem. Os resultados obtidos a partir de um Logit Ordenado e de um Logit Condicional mostram que existe uma significativa preferência dos consumidores da Coreia do Sul pela certificação e rotulagem de produtos de baixo carbono, sinalizando a preocupação com as questões de aquecimento global.

Todos esses estudos foram direcionados à captação da disposição a pagar para pessoas com relação às suas percepções ao valor de uso, valor de opção ou valor de existência para determinados recursos ambientais. A metodologia descrita a seguir permite analisar a disposição a pagar e o interesse de participação de um grupo de empresas gaúchas no mercado de carbono.

\section{METODOLOGIA}

Os dados utilizados neste trabalho provêm de uma pesquisa de campo realizada entre os meses de setembro de 2010 a janeiro de 2011. A amostra foi selecionada a partir do ranking elaborado pela empresa de consultoria Price water house Coopers, no ano de 2008, publicado pela Revista Amanhã (2009) com as 300 maiores empresas do Estado do Rio Grande do Sul classificadas com base no Valor Ponderado de Grandeza (VPG), que resulta da soma, com pesos específicos, dos três principais componentes do balanço patrimonial: patrimônio líquido (50\%), receita bruta $(40 \%)$ e resultado (lucro ou prejuízo) líquido (10\%).

Para atingir o objetivo da pesquisa, foram excluídos aqueles setores que não possuíam um nível de emissão de carbono elevado. Para isso, foi tomado como base o estudo realizado pela Fundação de Economia e Estatística (FEE), juntamente com a Fundação Estadual de Proteção Ambiental (FEPAM), que apresentou os indicadores de potencial poluidor da indústria gaúcha para os anos de 2002 a 2006. A seleção final totalizou 96 empresas.

A utilização do método de avaliação contingente partiu da aplicação de uma pesquisa junto às maiores empresas do estado do Rio Grande do Sul pertencentes ao setor industrial e com alto potencial poluidor. $O$ intuito da pesquisa foi de verificar o interesse dessas empresas em participar de um mercado voluntário de créditos de carbono.

Por meio dos dados coletados, pode-se avaliar não somente o grau de interesse de compensação de emissões pela compra de créditos de carbono, mas também valorar o quanto essas empresas estariam dispostas a pagar pelo certificado de redução, estando em linha ou não com o valor de mercado, dado que o certificado de redução de emissões equivale a compensação de 1 tonelada de $\mathrm{CO}^{1}{ }^{1}$.

Este trabalho se difere dos demais trabalhos que utilizaram o Método de Valoração Contingente, pois foi aplicado junto aos gestores de empresas, o que aumenta o grau de dificuldade na coleta de dados. Por outro lado, inova na técnica da percepção da disposição a pagar que teve que ser remodelada utilizando parâmetros até então pouco empregados.

Para captar o valor da disposição a pagar para a compensação da emissão de carbono pela empresa, foram utilizados alguns parâmetros específicos que comparam a equivalência de 1 tonelada de $\mathrm{CO} 2$ com alguns dos insumos utilizados no processo produtivo. Como 1 tCO2 equivale a 1 crédito de carbono negociado em bolsa, através dessa técnica, pode-se valorar o quanto a empresa estaria disposta a pagar pelo certificado negociável.

A tabela 1 apresenta a equivalência de emissão de $\mathrm{CO} 2$ em relação a energia elétrica, gasolina, diesel, lixo orgânico, gás natural e florestamento. Cabe ressaltar que os valores são aproximados e não necessariamente provêm da mesma fonte poluidora como é o caso de energia elétrica ${ }^{2}$. Além disso, as quantidades equivalentes foram calculadas com base no preço médio de mercado, considerado no período

\footnotetext{
${ }^{1}$ Dióxido de carbono.

2 De acordo com o Ministério de Minas e Energia, a energia elétrica no Brasil pode provir de diversas fontes como hídrica, térmica, eólica, fotovoltaica, das marés e nuclear, variando o nível de emissão em cada alternativa (MME, 2009)
} 
da coleta, como é o caso do diesel e da gasolina. Os parâmetros são apenas referência para tomada de decisão sobre a DAP.

TABELA 1 - Fontes de emissão e equivalência de CO2

\begin{tabular}{l|l|l}
\hline \multirow{2}{*}{ Emissão } & Equivalência & \multirow{2}{*}{ Unidade } \\
\cline { 2 - 3 } & \multicolumn{1}{|c}{$(\mathbf{1}$ tCO2) } & \\
\hline Energia elétrica & 2535 & $k W h$ \\
\hline Gasolina & 425 & litros \\
\hline Diesel & 385 & litros \\
\hline Lixo orgânico & 566 & $\mathrm{Kg}$ \\
\hline Gás natural & 188 & therms \\
\hline Árvore & 6 & unidades \\
\hline Hectare plantado* & 0,0033 & hectares \\
\hline
\end{tabular}

FONTE: Carbon foot print, 2011. Elaborado pelos autores

* 1666 árvores

De acordo com a tabela 1, uma tonelada de CO2 equivale à utilização de 2535 kwh de energia elétrica, 425 litros de gasolina, 385 litros de diesel, $566 \mathrm{Kg}$ de lixo orgânico, 188 therms de gás natural ou ao plantio de aproximadamente 6 árvores. $O$ último item foi inserido, pois muitas empresas já têm a prática de florestamento ou reflorestamento para compensar suas emissões. Nesses casos específicos, foi considerada a troca do plantio pela compra de créditos de carbono, mesmo que o REDD ${ }^{3}$ ainda esteja em discussão como instrumento para a compensação de emissões.

Ao realizar as entrevistas todos foram esclarecidos quanto à situação climática global e a possibilidade de compensação das emissões através da aquisição de créditos de carbono. Com o objetivo de testar o questionário, para detectar algum tipo de erro em sua construção, foram realizadas 7 entrevistas em uma pesquisa-piloto, sendo que estas não foram incluídas no grupo selecionado. As entrevistas foram feitas em sua maior parte pelo próprio autor com o auxílio de uma equipe devidamente treinada para esse fim.

Todos os questionários foram respondidos por uma pessoa ou grupo de pessoas com alto grau de responsabilidade e autonomia sobre a empresa, de preferência com características de diretor, sócio ou gerente. Para a elaboração do questionário, foram utilizadas perguntas fechadas englobando todas as respostas possíveis, para facilitar a tabulação e evitar viés de informação. Todas as perguntas estão relacionadas com o objetivo do estudo, formuladas de maneira clara com uma única interpretação.

A classificação setorial escolhida foi a mesma utilizada na base de dados encontradas no grupo estudado. A classificação do faturamento anual foi feita com base na metodologia utilizada pelo Banco Nacional de Desenvolvimento (2010). Os projetos de redução de poluentes foram escolhidos com base nos principais projetos negociados nos principais mercados voluntários de carbono (Ecosystem Market Place, 2010). As demais perguntas compõem variáveis explicativas complementares para identificar as principais razões do objetivo deste trabalho.

Para medir a disposição a pagar dos entrevistados, formulou-se a seguinte pergunta: Havendo a possibilidade de compensar as emissões de $\mathrm{CO} 2$ geradas pela empresa através da compra de créditos de carbono (sendo que 1 crédito de carbono equivale a compensação de 1 tCO2), você acredita que a empresa teria interesse em investir voluntariamente na aquisição desses créditos de carbono em troca da "emissão zero"?

A disposição a pagar foi captada utilizando o modelo referendum baseado na abordagem de Hanemman (1984), em que são oferecidos valores aleatórios aos entrevistados com o objetivo de captar o comportamento do indivíduo maximizador.

Quando o entrevistado respondia SIM, atribuía-se o valor 1 e, no caso da resposta ser negativa, aplicou-se um valor 0 .

Partindo do pressuposto de que os indivíduos derivam sua função utilidade para a aceitação entre participar ou não de um mercado voluntário de carbono a partir do faturamento e de outros atributos microeconômicos como a presença de um sistema de gestão ambiental, a função pode ser representada por $\mathrm{U}=\mathrm{U}(\mathrm{J}, \mathrm{Y}, \mathrm{S})$, onde $\mathrm{J}$ é uma variável binária:

$\mathrm{J}=1:$ o indivíduo aceita participar de um mercado de carbono;

$\mathrm{J}=0$ : o indivíduo não aceita participar de um mercado de carbono

$\mathrm{Y}=$ Faturamento;

\footnotetext{
${ }^{3}$ O REDD (Redução de Emissão por Desmatamento e Degradação) está sendo estudado como instrumento de compensação a ser negociado no âmbito do Protocolo de Quioto (Varghese, 2009).
} 
$\mathrm{S}=$ vetor de outros atributos que influenciam a DAP.

Dessa forma, a função utilidade pode ser representada por:

$\mathrm{U} 0=\mathrm{U}(0, \mathrm{Y}, \mathrm{S})-\mathrm{o}$ indivíduo não aceita participar

$\mathrm{U} 1=\mathrm{U}(1, \mathrm{Y}, \mathrm{S})-\mathrm{o}$ indivíduo aceita participar

As funções acima são variáveis aleatórias com distribuição de probabilidade e médias $v(0, Y, S)$, de modo que:

$\mathrm{U}(\mathrm{J}, \mathrm{Y}, \mathrm{S})=\mathrm{v}(\mathrm{J}, \mathrm{Y}, \mathrm{S})+\varepsilon j \mathrm{~J}=0,1$ quando:

$\varepsilon 0$ e $\varepsilon 1$ são variáveis independentes, com média zero e variância finita. A resposta afirmativa ocorre

$$
\mathrm{U} 1(1, \mathrm{Y}-\mathrm{P}, \mathrm{S})-\mathrm{v}(0, \mathrm{Y}, \mathrm{S}) \geq \mathrm{U} 0(0, \mathrm{Y}, \mathrm{S})
$$

A resposta do indivíduo é uma variável aleatória com uma distribuição de probabilidade dada por:

$$
\begin{aligned}
& \mathrm{P} 1=\mathrm{P}(\text { aceitar }) \\
& \mathrm{P} 1=\mathrm{P}[\mathrm{v}(1, \mathrm{Y}-\mathrm{P}, \mathrm{S})+\varepsilon 1 \geq \mathrm{v}(0, \mathrm{Y}, \mathrm{S})+\varepsilon 0] \\
& \mathrm{P} 1=\mathrm{P}[\mathrm{v}(1, \mathrm{Y}-\mathrm{P}, \mathrm{S})-\mathrm{v}(0, \mathrm{Y}, \mathrm{S}) \geq \varepsilon 0-\varepsilon 1]
\end{aligned}
$$

Considerando:

$$
\begin{aligned}
& \Delta v=v(1, Y-P, S)-v(0, Y, S) \text { e } \delta=\varepsilon 0-\varepsilon 1 \\
& P 1=P\{\Delta v \geq \delta\} \\
& P 0=P \text { (não participa) }
\end{aligned}
$$

Considerando $\mathrm{F} \delta($. ) a probabilidade do entrevistado a aceitar o valor $\mathrm{R} \$$, tem-se que $\mathrm{P} 1=\mathrm{F} \delta($. ).

\subsection{Modelo econométrico}

Dois modelos econométricos foram utilizados para atingir os objetivos deste estudo. Com base em Gujarati (2002), o primeiro é dado por:

$$
Y=X \beta+e
$$

em que, $Y$ corresponde a um vetor contendo as disposições a pagar manifestadas (maior lance aceito) em $\mathrm{R} \$ ; \quad X$ representa um vetor de variáveis exógenas (faturamento, presença de um setor ambiental, certificação ambiental); $\beta$ representa um vetor de parâmetros desconhecidos a serem estimados pelo método dos mínimos quadrados ordinários (MQO); e "e" é o erro aleatório com as pressuposições usuais.

O segundo é o modelo logit, que possibilita estimar a probabilidade de cada variável independente em explicar a disposição a pagar pelo indivíduo (empresa). Nesse modelo, estima-se, primeiro, a probabilidade de um indivíduo se dispor a pagar. Esse modelo está baseado na função de probabilidade logística acumulada, representada da seguinte forma:

$$
P i=E(Y=1 \mid X i)=\frac{1}{1+e^{-(\beta 1+\beta 2 X i)}} P i=E(Y=1 \mid X i)=\frac{1}{1+e^{-}}
$$

em que $X$ é um vetor de variáveis explicativas; $\beta$, parâmetros desconhecidos a serem estimados; e $\mathrm{Pi}$ probabilidade de o indivíduo i responder "sim" à indagação se está disposto a pagar para compensar a emissão de 01 tCO2. A variável Pi não é observada. Observa-se Yi=1, quando o indivíduo responder "sim" e $\mathrm{Yi}=0$, quando o a resposta for "não".

A equação (12) pode ser reescrita como:

$$
P i=\frac{1}{1+e^{-Z i}}
$$

Zi varia entre - $\infty$ e $\infty$, Pi varia entre 0 e 1 e é não-linearmente relacionado com Zi. Considerando que Pi é a probabilidade de aceitação do indivíduo de um determinado valor, então (1 - Pi) é:

$$
\begin{aligned}
& 1-P i=\frac{1}{1+e^{-Z i}} \\
& \frac{P i}{1-P i}=\frac{1+e^{Z i}}{1+e^{-Z i}}=e^{Z i}
\end{aligned}
$$

Nesse caso, $P i=(1-P i)$ é a razão entre a probabilidade de aceitação do valor e a probabilidade de não aceitação. Tomando-se o logaritmo natural da expressão acima, chega-se a:

$$
L i=\ln \frac{P i}{1-P i}=Z i=\beta 1+\beta 2 X i
$$


Onde $\mathrm{L}$ é o logaritmo da razão $P i /(1-P i)$ e é não apenas linear em $\mathrm{X}$, mas também nos parâmetros. L é denominado logit, razão da denominação do modelo.

O modelo logit, conforme Aguirre e Faria (1996), será interpretado como resultado de uma escolha que maximiza a utilidade. A função $F \delta($. ) deve ter a forma (16), condição que é análoga às condições da teoria da demanda.

Calculando $\Delta v$, pode-se determinar o modelo estatístico discreto de escolha, supondo que:

$$
\begin{aligned}
& \Delta v=v(1, Y-P, S)-v(0, Y, S) \\
& v(J, Y, S)=a j(s)+b(y) c o m ~ J=0,1 \text { e } b>0 \\
& \Delta v=a 1(s)+b(Y-P)-a 0(s)-b Y \\
& \Delta v=[a 1(s)-a 0(s)-b P] \\
& \Delta v=[(a 1-a 0)-b P] \\
& \Delta v=a-b P
\end{aligned}
$$

Assim, o modelo estatístico discreto de escolha binária seria:

$$
\begin{aligned}
& \mathrm{P} 1=\mathrm{F} \delta(\Delta \mathrm{v}) \\
& \mathrm{P} 1=\mathrm{F} \delta(\mathrm{a}-\mathrm{b} \mathrm{P})
\end{aligned}
$$

e deve satisfazer à seguinte igualdade:

$$
\mathrm{U}\left(1, \mathrm{Y}-\mathrm{P}^{*}, \mathrm{~S}\right)=\mathrm{U}(0, \mathrm{Y}, \mathrm{S}) \text {, ou seja }
$$$$
v\left(1, Y-P^{*}, S\right)-v(0, Y, S)=\delta
$$

$\delta$ tem uma distribuição logística padronizada com média e mediana iguais a zero. Assim, considerando que $\Delta v=\delta=0$ e $\mathrm{P}^{*}$ como o valor médio representativo da disposição a pagar do indivíduo:

$$
\begin{aligned}
& \Delta \mathrm{v}\left(\mathrm{P}^{*}\right)=0 \\
& \mathrm{a}-\mathrm{bp}=0 \\
& P=\frac{a}{b}=D A P
\end{aligned}
$$

A equação (29) representa a DAP, ou seja, indica que o valor médio (mediano) é calculado em função dos coeficientes do modelo estatístico discreto de escolha binária. No caso em que o modelo apresente mais de uma variável independente, o denominador será o parâmetro da variável preço e o numerador, o intercepto mais os valores médios das demais variáveis, multiplicado pelos seus respectivos parâmetros.

\section{ANÁLISE DOS RESULTADOS}

\subsection{Características gerais das empresas entrevistadas}

Das 96 empresas selecionadas para a pesquisa, apenas 6 se recusaram a responder ao questionário, resultando num total de 90 empresas entrevistadas. Entre as justificativas para a não participação, estariam o sigilo empresarial e a grande dificuldade de encontrar um entrevistado com respaldo suficiente para responder às questões envolvidas.

O grupo de estudo é representado por 12 setores distintos. A maior parte das empresas se concentra no setor de Alimentos e Bebidas, Metalurgia e Automotivo, que representam mais de $50 \%$ do total. $O$ resumo setorial está ilustrado na figura 1.

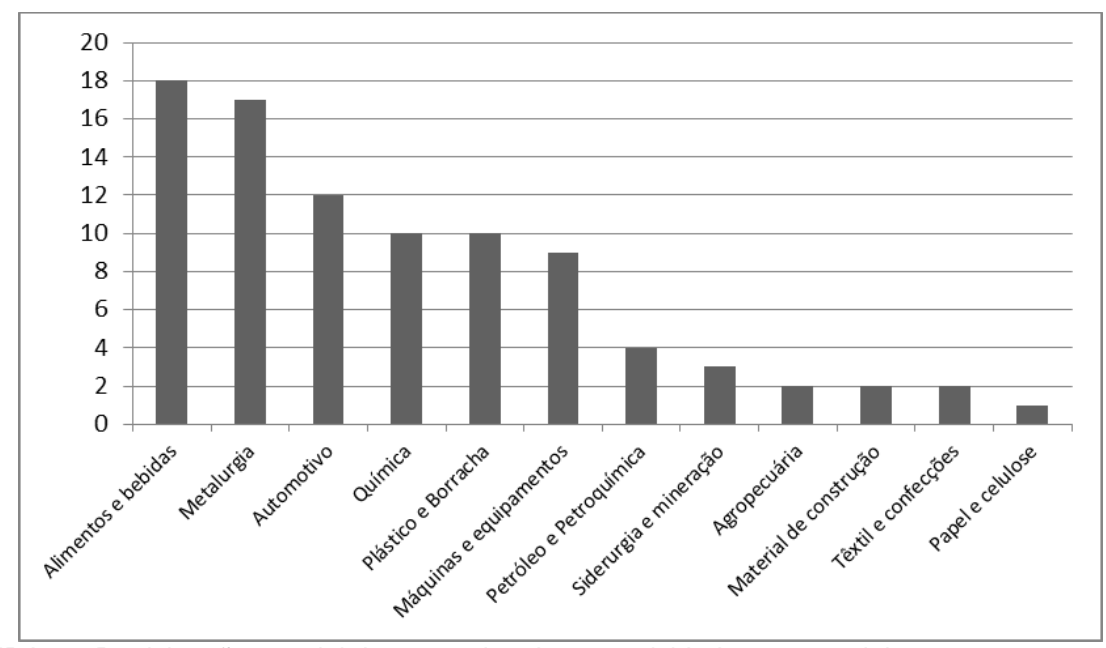

FIGURA 1 - Participação setorial dos entrevistados por atividade empresarial FONTE: resultados da pesquisa. 
Com relação ao faturamento, a maior parte das empresas tem um faturamento abaixo de $\mathrm{R} \$ 90$ milhões por ano (44,4\%), enquanto $25,6 \%$ faturam entre $R \$ 90$ a $R \$ 300$ milhões e $30 \%$ das empresas têm faturamento anual acima de $\mathrm{R} \$ 300$ milhões. Interessante observar que o faturamento médio das 10 maiores empresas fica em torno de $\mathrm{R} \$ 7,7$ bilhões enquanto que o restante, excluindo o grupo das 10 maiores, tem um faturamento médio de $\mathrm{R} \$ 200$ milhões, muito abaixo das primeiras, evidenciando a desigualdade do grupo. Considerando apenas os grupos mais representativos, aqueles com mais de $10 \%$ do total, o setor automotivo é o que possui a maior parte das empresas com faturamento abaixo de $\mathrm{R} \$ 90$ milhões, com $26 \%$. Já o setor de alimentos e bebidas é o que tem a parcela maior de empresas que faturam entre $\mathrm{R} \$ 90 \mathrm{e}$ $\mathrm{R} \$ 300$ milhões com $32 \%$ e o setor de metalurgia é o que tem a maior parcela de empresas que faturam mais de $\mathrm{R} \$ 300$ milhões com $32 \%$.

Do total de empresas entrevistadas, apenas $22,2 \%$ têm sociedade com capital aberto. Das empresas que têm capital aberto, todas possuem um setor responsável pela área ambiental, o que é esperado das empresas com maior rigor em cumprimento nos processos, visando a um menor impacto ambiental. Do total da amostra, $75,6 \%$ das empresas possuem um sistema de gestão ambiental, enquanto $24,4 \%$ não possuem. Além disso, apenas $22,2 \%$ das empresas possuem a certificação ambiental ISO 14.001 , certificado que representa uma série de normas desenvolvidas pela International Organization for Standardization (ISO) e estabelecem diretrizes sobre a área de gestão ambiental dentro das empresas. Isso demonstra que a maioria das empresas possuem algum tipo de projeto de redução de poluentes, mas dado o rigor para a implantação de um sistema de gestão qualificado, caso do ISO 14.001 , poucas empresas investem na qualificação (ISO, 2010).

Conforme Carvalho et al., (1996, p. 38), o sistema de gestão ambiental:

[...] constitui parte integral do gerenciamento total de uma organização, que reconhece a qualidade de seu desempenho ambiental como um fator-chave para a sua capacidade de prosperar, arquitetando um sistema para identificar, examinar e avaliar, sistematicamente, as mudanças ambientais causadas por aspectos ou elementos de seus produtos, serviços e atividades.

Ainda dentro do aspecto de gestão ambiental, $95,6 \%$ do total das empresas possuem algum projeto de tratamento ou redução de poluentes, mesmo aquelas que não têm um sistema de gestão ambiental. $A$ Figura 2 mostra os principais projetos utilizados pelas empresas. O projeto de tratamento de resíduos é o mais utilizado pelo grupo, representando $31 \%$ do total, seguido pelo projeto de Reaproveitamento de Material (15\%), Eficiência Energética (13\%) e Tratamento de Efluentes (13\%). Os outros projetos como Lixo Seletivo, Florestamento ou Reflorestamento, Compostagem e Gases Diversos somados representam 28\% do total do grupo.

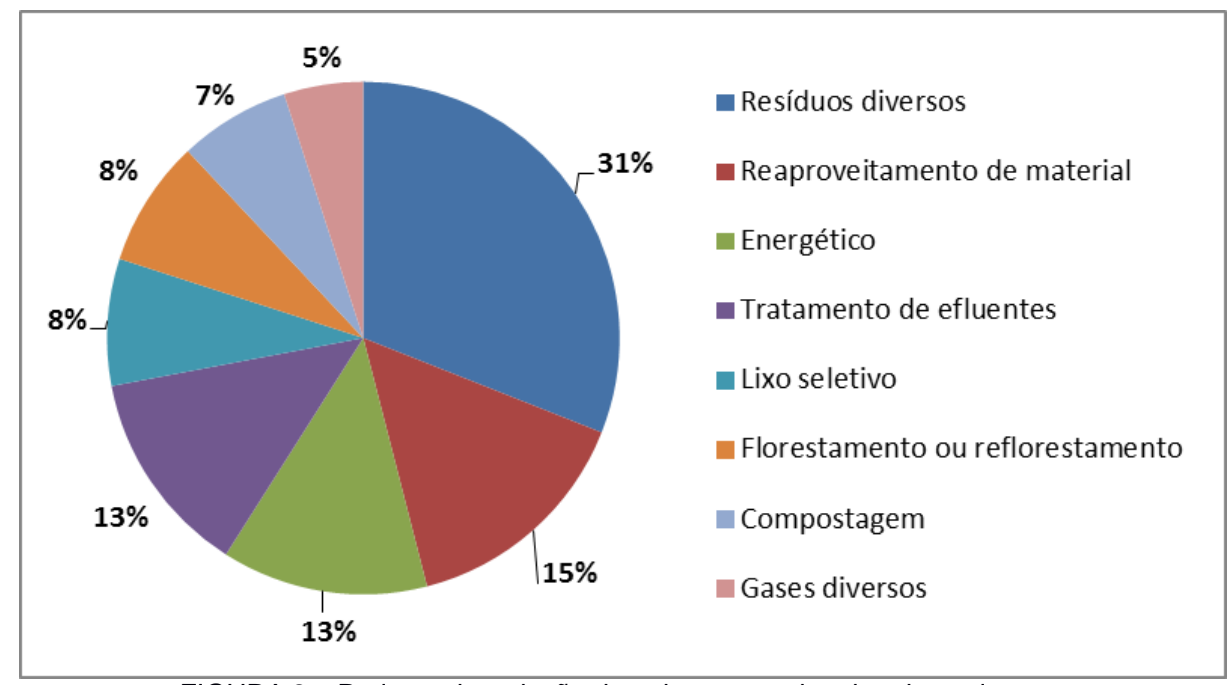

FIGURA 2 - Projetos de redução de poluentes mais adotados pelas empresas FONTE: Resultados de pesquisa.

A explicação para a maior parte de as empresas adotar como principais projetos o tratamento de resíduos, o reaproveitamento de material e o energético, pode ser não só pelos cuidados necessários com o meio ambiente, mas também pelo benefício da redução de custos com o reaproveitamento de material reutilizável e controle de desperdício de energia. Um exemplo de políticas públicas que estimulam a maior eficiência energética por parte das empresas é o Programa Nacional de Conservação de Energia Elétrica (PROCEL). O PROCEL, iniciado em 1985, vem desenvolvendo programas para reduzir o consumo de 
energia pelas indústrias e aumentar a eficiência energética através de um conjunto de ações e iniciativas. Com o estímulo ao desenvolvimento de novas tecnologias, segurança energética e eficiência econômica, o PROCEL apresenta uma contribuição significativa no estímulo ao melhor uso energético e à redução dos impactos ambientais oriundos da atividade econômica (Vianna, Ramos e Pereira, 2010).

Apesar de ser um dado satisfatório, muitas das práticas de cuidado com poluentes adotadas pelas empresas não são espontâneas, mas indispensáveis para a prática do negócio, sendo, em muitos casos, controladas pela FEPAM, que é responsável pelo licenciamento ambiental no Rio Grande do Sul. Isso quer dizer que, não necessariamente, a empresa adota projetos de redução de poluentes por livre e espontânea vontade, mas, em muitos casos, por obrigatoriedade legal.

Quando questionadas sobre o conhecimento da Lei 12.187/09, que instituiu a Política Nacional sobre Mudança do Clima (PNPC) e visa reduzir entre $36,1 \%$ e $38,9 \%$ as suas emissões com base na projeção para 2020 e o direcionamento de diversas ações efetivas, apenas $12,2 \%$ das empresas desconheciam essa lei, enquanto que o restante, $87,8 \%$, detinha o conhecimento sobre a regulamentação. $O$ resultado esperado está em linha com o fato de que as empresas são incentivadas a terem um sistema de gestão ambiental e demonstra que há uma preocupação com possíveis regulamentações mais rígidas no futuro. A regulamentação adequada pode influenciar diretamente na tomada de decisão da empresa quanto a participar de um mercado de carbono ou reduzir seus níveis de emissão de maneiras alternativas com tecnologias mais limpas.

\subsection{Interesse de participação no mercado}

Depois de introduzir a ideia de compensação das emissões de GEE da empresa com a compra de créditos de carbono, foi questionado se estariam dispostas a participar de um mercado de carbono de forma voluntária. Das 90 empresas entrevistadas, 56 têm interesse de participar de um mercado de carbono, o que representa $62,2 \%$ do total, enquanto que 34 responderam que não visam a esse interesse. $O$ resultado mostra que o grupo estudado possui um mercado potencial de créditos de carbono a ser explorado.

Dos setores que mais apresentaram interesse de participação, destaca-se o de Máquinas e Equipamentos, com $90 \%$ de interesse de participação, seguido pelo setor de Alimentos e Bebidas com $71 \%$. Os demais setores tiveram em torno de $50 \%$ de interesse de participação. Das empresas que faturam até $\mathrm{R} \$ 90$ milhões por ano, $68 \%$ responderam que têm interesse de participação do mercado, enquanto que $52 \%$ tiveram uma resposta afirmativa no grupo entre $R \$ 90$ e $R \$ 300$ milhões e no grupo com mais de $R \$ 300$ milhões, $63 \%$ tiveram uma resposta afirmativa. Com relação às empresas que têm um setor responsável pela área ambiental, $69,1 \%$ têm interesse em participar do mercado de carbono, resultado que está em linha com o esperado visto que empresas que têm um sistema de gestão ambiental possuem um conhecimento mais profundo sobre o assunto.

Para identificar a motivação das empresas em participar de um mercado de carbono, foram realizadas algumas perguntas cujas respostas eram classificadas por grau de relevância. Conforme a tabela 2, a principal motivação das empresas está na preservação do meio ambiente, com $64,3 \%$ das respostas justificadas com "muito alto" grau de relevância. Os itens Responsabilidade Social e Incremento de Valor da Marca somaram, respectivamente, $57,1 \%$ e $35,7 \%$ na categoria "muito alto". Com menor propósito de motivação, estão os itens: pré-regulamentação, facilitar a redução das emissões e investimento/venda futura.

TABELA 2 - Propósito para a participação em um mercado de carbono

\begin{tabular}{l|c|c|c|c|c}
\hline Propósito & Muito baixo & Baixo & Médio & Alto & Muito alto \\
\hline Investimento / Venda Futura & 17,90 & 44,60 & 17,90 & 14,30 & 5,40 \\
\hline Facilitar a Redução das Emissões & 25,00 & 19,60 & 28,60 & 19,60 & 7,10 \\
\hline Pré-regulamentação & 16,10 & 30,40 & 30,40 & 17,90 & 5,40 \\
\hline Responsabilidade Social & - & 1,80 & 16,10 & 25,00 & 57,10 \\
\hline Valor à Marca & 5,40 & 14,30 & 19,60 & 25,00 & 35,70 \\
\hline Preocupação com Meio Ambiente & - & - & 8,90 & 26,80 & 64,30 \\
\hline
\end{tabular}

FONTE: resultados de pesquisa.

Estes resultados podem indicar um baixo grau de conhecimento sobre os mercados de carbono para este grupo de empresas estudado. Os três itens menos votados referem-se justamente a questões de regulamentação ambiental e valorização do preço do crédito de carbono, que só serão mais vislumbrados a partir de um avanço nas metas do governo brasileiro para a redução das emissões.

Interessante salientar que os itens mais votados refletem a postura da empresa junto ao consumidor 
e o seu papel social. A alta preocupação com o meio ambiente dá sinais de uma preocupação maior com o risco climático global.

Já os motivos alegados para a não participação num mercado de carbono estão descritos na tabela 3. Com $29,4 \%$ do total, a falta de regulamentação e a obrigatoriedade de controle dos níveis de emissão não incentivam a participação neste tipo de mercado. A falta de maiores informações e conhecimento sobre o assunto representou $26,5 \%$ dos casos. Aqui, salienta-se o despreparo de empresas que ainda não se adequaram a um novo modelo de produção mais limpa e a falta de ações por parte dos órgãos públicos responsáveis para fomentar um modelo ambiental adequado.

TABELA 3 - Motivo alegado para a não participação em um mercado de carbono

\begin{tabular}{l|c|c}
\hline Motivo por não participar & Frequência & $\%$ \\
\hline Apenas com regulamentação & 10 & $29,4 \%$ \\
\hline Falta de informação ou conhecimento & 9 & $26,5 \%$ \\
\hline Já possuir projetos sustentáveis & 7 & $20,6 \%$ \\
\hline Acredita já possuir uma matriz limpa & 3 & $8,8 \%$ \\
\hline Não acredita na deterioração do M.A. & 2 & $5,9 \%$ \\
\hline Não acredita no sistema de mercado & 2 & $5,9 \%$ \\
\hline Não acredita em retorno & 1 & $2,9 \%$ \\
\hline TOTAL & 34 & $100,0 \%$ \\
\hline FONTE: Resultados de pesquisa. & &
\end{tabular}

Uma parte das empresas, $20,6 \%$ do total, alega já possuir uma matriz sustentável que não agride o meio ambiente, mesmo fazendo parte dos setores com alto potencial poluidor. Uma investigação mais acurada poderia justificar se este motivo não tem a ver com um despreparo dessas empresas por uma visão mais limpa de produção. O restante das justificativas envolve razões como falta de credibilidade na sistemática dos mercados de carbono, retorno financeiro que justifique a participação e, até mesmo, dúvidas com relação à real deterioração do meio ambiente.

Os entrevistados que estão dispostos a participar do mercado foram questionados quanto ao valor máximo que pagariam para 1 certificado de redução de carbono, que equivale à redução de 1 tCO2. Conforme os parâmetros de comparação, apresentados anteriormente, foram oferecidos lances a partir de $\mathrm{R} \$ 0,25$. Caso o entrevistado aceitasse esse valor, era oferecido um valor superior até a negação da DAP, quando se chegaria ao valor máximo aceitável. Alguns entrevistados responderam que pagariam simplesmente o valor de mercado do crédito de carbono, neste caso, o valor aproximado de $\mathrm{R} \$ 34,00$.

Os resultados econométricos para a DAP manifestada encontram-se na tabela 4. Esse tipo de análise visa a observância do maior lance que os indivíduos estariam dispostos a pagar. A partir dela, pode-se verificar as variáveis que influenciam a DAP máxima. O método utilizado para verificar o comportamento das variáveis é o Mínimos Quadrados Ordinários (MQO), com correção de heterocedasticidade pelo método de White.

TABELA 4 - Resultados econométricos para a DAP manifestada ${ }^{4}$

\begin{tabular}{|l|r|r|r|r|}
\hline Variável & \multicolumn{1}{|c|}{ Coeficiente } & Desvio-padrão & \multicolumn{1}{c|}{ Estatística t } & \multicolumn{1}{c|}{ p-valor } \\
\hline C & 7.276573 & 4.244859 & 1.714209 & 0.09 \\
\hline Faturamento & $0.012800^{\star}$ & 0.006485 & 1.973891 & 0.05 \\
\hline Setor Ambiental & $9.456047^{\star *}$ & 5.151773 & 1.835494 & 0.07 \\
\hline Certificação Ambiental & $-4.061388 \mathrm{NS}$ & 4.215888 & -0.963353 & 0.33 \\
\hline R-quadrado & 0.145422 & Média da variável dependente & 18.24107 \\
\hline R-quadrado ajustado & 0.096119 & Desvio-padrão da variável dependente & 14.71502 \\
\hline Desvio-padrão da regressão & 13.98995 & Estatística F & 2.949583 \\
\hline Estatística Durbin-Watson & 2.031710 & Probabilidade (estatística F) & 0.041144 \\
\hline
\end{tabular}

* Significativo a 5\%; ** Significativo a 10\%; NS parâmetro não-significativo

FONTE: resultados de pesquisa.

\footnotetext{
${ }^{4}$ C é o intercepto; DAP é a variável dependente e corresponde a disposição máxima a pagar das empresas; Faturamento: é o faturamento expresso em milhões de reais; Setor ambiental: Dummy representativa dos indivíduos que possuem um setor responsável pela área ambiental. Será 1 se possuir e 0 caso contrário; Cert. ambiental: Dummy representativa dos indivíduos que possuem a certificação ambiental. Será 1 se possuir e 0 caso contrário. Número de observações: 54 .
} 
A variável dependente contínua é de disposição máxima a pagar de acordo com os lances oferecidos. A variável explicativa faturamento é expressa em milhões de reais e foi utilizado o faturamento individual das empresas agrupadas em faixas específicas: até $R \$ 50$ milhões, até $R \$ 100$ milhões, até $R \$ 200$ milhões, até $R \$ 500$ milhões, até $R \$ 1$ bilhão e acima de $R \$ 1$ bilhão.

Conforme explicado pelo modelo, uma variação de $R \$ 10$ milhões no faturamento da empresa aumenta em torno de $\mathrm{R} \$ 0,13$ no valor pago para a compensação de $01 \mathrm{tCO} 2$. Ou seja, quanto maior o faturamento anual da empresa, maior o valor aceito para compensar a emissão de 1 tCO2.

Esse resultado pode ter duas implicações, a primeira é que as empresas com maiores recursos financeiros direcionam uma quantidade maior de capital para práticas ambientais. A segunda é que as empresas maiores podem ter uma percepção melhor sobre preço justo que já é negociado nos mercados de carbono.

A disposição a pagar média encontrada para o grupo de empresas ficou em $\mathrm{R} \$ 18,24$, abaixo do valor médio negociado no mercado europeu, que se encontra em torno de $R \$ 34,00$. O preço médio do carbono encontrado neste estudo pode ser explicado pela heterogeneidade dos setores, que implica uma matriz de custos bastante distinta. Além disso, o grupo possui diferenças relevantes no faturamento médio.

A variável Setor Ambiental obteve um coeficiente positivo, em linha com o esperado pelo modelo, visto que empresas que têm um sistema de gestão ambiental estão mais aptas a participar de um mercado de carbono, seja pela preparação para uma produção mais limpa, como pela responsabilidade social.

$O$ coeficiente de determinação $R^{2}$ para esse modelo foi relativamente baixo $(0,14)$. Entretanto, esse resultado se assemelha a outros resultados obtidos em estudos similares, justificado, por alguns autores, pela não observância de um padrão de determinação no lance máximo dado pelos indivíduos (Gujarati, 2002). Além disso, o tamanho da amostra pode ter influência direta, justificando a realização de outros estudos que contenham uma participação maior de observações.

Utilizando o modelo Logit, estimou-se a verdadeira disposição a pagar da empresa. O resultado do modelo encontra-se descrito na tabela 05.

TABELA 5 - Resultados encontrados pela estimação do modelo Logit ${ }^{5}$

\begin{tabular}{l|r|r|r|r|}
\hline Variable & \multicolumn{1}{|c|}{ Coeficiente } & Desvio-padrão & \multicolumn{1}{c|}{ Estatística Z } & \multicolumn{1}{c|}{ p-valor } \\
\hline C & -0.875904 & 0.769806 & -1.137825 & 0.2552 \\
\hline Faturamento & $-0.001595^{*}$ & 0.000716 & -2.228425 & 0.0259 \\
\hline Setor ambiental & $1.371835^{*}$ & 0.570226 & 2.405775 & 0.0161 \\
\hline Conhecimento regulamentação & 1.083186 & 0.810007 & 1.337254 & 0.1811 \\
\hline R-quadrado McFadden & 0.094562 & Log likelihood & -54.02467 \\
\hline Estatística LR (3 df) & 11.28450 & Média log likelihood & -0.600274 \\
\hline Probabilidade (Estatística LR) & 0.010283 & Restr. log likelihood & -59.66692 \\
\hline
\end{tabular}

* Significativo a 5\%; NS parâmetro não-significativo.

FONTE: resultados de pesquisa.

Os resultados encontrados pelo modelo Logit mostram que a probabilidade de as empresas participarem de um mercado de carbono diminui conforme o faturamento anual das empresas aumenta. Isso significa que é mais provável que empresas pequenas tenham mais interesse em compensação das emissões via compra de créditos de carbono, apenas das empresas menores se disporem a pagar menos pela tonelada de $\mathrm{CO} 2$.

A presença de um sistema de gestão ambiental, definido pela variável Setor Ambiental, aumenta a probabilidade de participação no mercado de carbono em 137\%, conforme os resultados do modelo.

\section{CONCLUSÃO}

A redução de emissões por parte das maiores empresas do Brasil encontra-se ainda em processo lento, devido principalmente à falta de regulamentação e de políticas públicas que visem incentivar a criação de um mercado de carbono padronizado. Em contrapartida, muitas empresas têm evoluído de maneira voluntária na busca por uma produção mais limpa, sendo beneficiadas por retornos financeiros e com uma postura ecológica frente à sociedade.

Nesse contexto, tem-se o exemplo bem-sucedido da indústria arrozeira e da produção de suínos no estado do RS em reduzir a emissão de gases de efeito estufa. No caso do arroz, a Camil adotou novas

\footnotetext{
${ }^{5} \mathrm{C}$ é o intercepto; Variável dependente: dummy: 0 para não disposição a pagar e 1 para disposição a pagar afirmativa; Faturamento é a variável que corresponde ao faturamento anual; Setor ambiental: Dummy representativa dos indivíduos que possuem um setor responsável pela área ambiental. Será 1 se possuir e 0 caso contrário; Conhecimento Regulamentação: Dummy representativa dos indivíduos que tem conhecimento sobre a nova regulamentação do clima. Será 1 se possuir e 0 caso contrário.
} 
práticas e tecnologias visando utilizar o principal resíduo do beneficiamento do arroz para a geração de energia elétrica a partir da combustão da casca de arroz, evitando, assim, a emissão de metano para a atmosfera. Com objetivo semelhante, a produção de suínos na Master Agropecuária tem utilizado os resíduos sólidos dessa atividade para produzir energia elétrica a partir de biodigestores, também reduzida a emissão de gases do efeito estufa (SOUZA, ALVIM e SANTIN, 2011).

Este trabalho teve por objetivo avaliar a disposição a pagar que as maiores empresas do estado do Rio Grande do Sul têm para a compensação das emissões de CO2 com a participação em um mercado de carbono. Através de uma pesquisa de campo, foi aplicado o Método de Valoração Contingente, possibilitando chegar às seguintes conclusões:

- A população analisada se mostrou disposta a aceitar a compensação de suas emissões de $\mathrm{CO} 2$ através da compra de créditos de carbono, apesar de haver resistência principalmente pela falta de informação, conhecimento e de uma regulamentação adequada que crie metas compulsórias de redução;

- Entre as principais motivações que levaram a maior parte das empresas a aceitar a participação em um mercado de carbono estão a preocupação ambiental, seguida da valorização da marca e da responsabilidade social;

- O valor médio da DAP encontrada ficou em $\mathrm{R} \$ 18,24$, valor que está abaixo do preço médio praticado no mercado europeu, o que pode refletir uma falta de percepção do grupo sobre o assunto e também pode ser justificado pela heterogeneidade do grupo em questão. Estudos para grupos setoriais podem contribuir para uma análise de preço para cada instrumento de redução de carbono, de acordo com a principal atividade realizada pelo setor.

- De acordo com os resultados do modelo, as empresas maiores se dispõem a pagar um valor maior pelo crédito de carbono, mostrando que possuem uma percepção maior pelo preço negociado no mercado europeu. Os resultados do modelo logit mostraram que a probabilidade de aceitação é maior para empresas pequenas.

- A presença de um setor ambiental revela uma característica importante para aceitação da compensação de emissões. Os resultados do modelo logit mostraram que a probabilidade de participação em um mercado de carbono aumenta em 137\% para aquelas empresas que têm esse sistema de gestão ambiental. Essa informação vai em linha com a teoria, mostrando que empresas que inovam com uma produção mais limpa estariam mais aptas a compensação das emissões via instrumentos de mercado.

Este estudo contribui como um primeiro passo no sentido de valorar o potencial de um mercado voluntário de carbono através da participação de empresas com alto potencial poluidor. Contudo, pesquisas que envolvam um número de observações maior, inclusive aumentando o escopo para empresas ou setores de todo o país, seriam interessantes no sentido de ampliar e precisar resultados que possam servir como base de decisões econômicas. Como desafio para futuras pesquisas, está a relevância de avaliar esse mercado de carbono e propor alternativas positivas de maneira que as empresas não vejam essas iniciativas apenas como custos adicionais impostos pelos formuladores de políticas, mas sim como uma oportunidade de abrir novos mercados e ampliar a venda de produtos com baixa emissão de carbono.

\section{REFERÊNCIAS}

ABREU et al. Valoração Econômica: Aplicação do Método do Custo de Viagem para a Praia da Avenida em Maceió. In: 36ํㅡㄹ Encontro Nacional de Economia, 9 - 12 dez. 2008, Salvador (BA). Anais eletrônicos... Salvador.

AGUIRRE, A., FARIA, D.M.C. P. Avaliação contingente de investimentos ambientais: um estudo de caso. Estudos Econômicos, São Paulo, v. 26, n. 1, p 85-109, 1996.

AMANHÃ: Gestão, economia e negócios. As 500 maiores do sul. Porto Alegre: Ed. 257, set. 2009. Disponível em: http://www.amanha.com.br/grandeselideres. Acesso em: ago. 2010.

BANCO NACIONAL DE DESENVOLVIMENTO - BNDES. Porte da empresa. Disponível em: http://www.bndes.gov.br/SiteBNDES/bndes/bndes pt/Navegacao Suplementar/Perfil/porte.html. Acesso em: ago. 2010.

CARBONFOOTPRINT. Carbon Footprint Calculators. Disponível em: http://www.carbonfootprint.com/calculator1.html. Acesso em: jul. 2010.

CARVALHO, Alexandre B. M.; FROSINI, Luis H., FRAZÃO, Rogério. Sistema ISO de gestão ambiental. Revista Controle da Qualidade. São Paulo, n. 45, p. 30-46, fev. 1996.

ECOSYSTEM MARKETPLACE AND BLOOMBERG NEW ENERGY FINANCE. Building Bridges: State of the Voluntary Carbon Markets 2010. Jun. 2010.

FUNDAÇÃO DE ECONOMIA E ESTATÍSTICA - FEE. Atividades Industriais Gaúchas: Indicadores do Potencial 

http://www.fee.tche.br/sitefee/pt/content/estatisticas/pg indicadores economicos ambientais.php. Acesso em: jul. 2010. GUJARATI, D. N. Econometria Básica. São Paulo: Pearson Education do Brasil, 2002.

HANEMANNM, W. Michael. Discrete/Contingent Models of Consumer Demand. Econometrica vol. 52, n. 3, 1984a p. 541-561.

INTERCONTINENTAL EXCHANGE - ICE. Data Center. Disponível em: https://www.theice.com/marketdata/reports/datacenter.shtml. Acesso em: fev. 2011.

INTERNATIONAL ORGANIZATION FOR STANDARDIZATION - ISO. ISO 14000 Essentials. Disponível em: http://www.iso.org/iso/iso 14000 essentials. Acesso em: set. 2010.

HOLMES, T; ALGER, K; ZINKHAN, C; MERCER, E. The Effect of Response Time on Conjoint Analysis Estimates of Rainforest Protection Values. Journal of Forest Economics, vol 4. Issue 1, 1998.

KIM, H; HOUSE, L. A; KIM, T. K. Consumer Perceptions of Climate Change and Willingness to Pay for Mandatory Implementation of Low Carbon Labels: the case of South Korea. International Food and Agribusiness Management Review, vol. 19, issue 4, 2016.

MARTINS, G. N. O valor da preservação do Parque dos Manguezais em Recife-PE: uma utilização do método de opções reais. In: 35ํㅡㄹ Encontro Nacional de Economia, 4 - 7 dez. 2007, Recife (PE). Anais eletrônicos... Recife.

MINISTÉRIO DE MINAS E ENERGIA. Resenha Energética Brasileira. 2009. Disponível em: http://www.mme.gov.br/mme/galerias/arquivos/publicacoes/BEN/3 - Resenha Energetica/Resenha Energetica 2009 PRELIMINAR.pdf. Acesso em: jan. 2011.

MITCHELL, R. C. \& CARSON, R. T. Using surveys to value public goods: the contingent valuation method. Washington D.C.The Johns Hopkins University Press. 1989.

MMA, MAPA, MME, MF, MDIC, MCT, MRE, Casa Civil, 2009; Cenários para Oferta Brasileira de Mitigação de Emissões. São Paulo, 13 de novembro.

PEREIRA JÚNIOR, J. C. Valoração Econômica Ambiental - Conceitos e Métodos. Pará, 2005.

SERÔA DA MOTTA, R. Manual de Valoração Econômica de Recursos Ambientais. Brasília: MMA, 1997.

SOUZA, O. T.; ALVIM, A. M; CALANDRO, M. L. As Dinâmicas da Economia Regional: métodos de análise e configurações contemporâneas da economia gaúcha. In: Osmar Tomaz de Souza; Augusto Mussi Alvim; Maria Lucrécia Calandro. (Org.). Os Desafios do Desenvolvimento: tendências e perspectivas para a economia gaúcha. 1ed. Porto Alegre: Editora Universitária - EDIPUCRS, 2011, v. 1, p. 9-13.

SOUZA, R. F. P. Valoração Econômica Ambiental: o caso do Rio Paraibuna, Juiz de Fora - MG. In: 34ํㅡㄹ Encontro Nacional de Economia, 5 - 8 dez. 2006, Salvador (BA). Anais eletrônicos... Salvador.

UNFCCC. Convenção sobre Mudança do Clima. 2.ed. Brasília: MCT, 2001a. 30p. Disponível em: http://www.mct.gov.br/index.php/content/view/3996.html. Acesso em: Nov. 2010.

VARGHESE, Paul. An Overview of REDD, REDD plus and REDD readiness. International Conference on Community Rights, Forests and Climate Change. New Delhi, 17-18 Ago. 2009. Disponível em: http://www.rightsandresources.org/documents/files/doc 1220.pdf. Acesso em: set. 2010.

VIANNA, L. G. V.; RAMOS, M. O. S.; PEREIRA, O. S. Programa de Conservação de Energia Elétrica, seus Desdobramentos e Necessidades para Consolidação. In: Energia 2030: desafios para uma nova matriz energética, 8 a 10 de dez. 2010, São Paulo (SP). VII CBPE, São Paulo. 